\title{
Developmentally programmed induction of differentiation inhibiting activity and the control of stem cell populations
}

\author{
Peter D. Rathien ${ }^{1,6}$, Jennifer Nichols ${ }^{2,3}$, Sara Toth ${ }^{1,4}$, Dylan R. Edwards ${ }^{1,5}$, John K. Heath ${ }^{1}$, and \\ Austin G. Smith ${ }^{1,3,7}$ \\ ${ }^{1}$ CRC Growth Factors Group, Department of Biochemistry, University of Oxford, Oxford OXI 3QU, UK; ${ }^{2}$ ICRF \\ Developmental Biology Unit, Department of Zoology, University of Oxford, Oxford OX1 3PS, UK; ${ }^{3}$ AFRC Centre for Genome \\ Research, University of Edinburgh, Edinburgh EH9 3JQ, UK; ${ }^{4}$ Department of Biology, Semelweis University, Budapest 1445 , \\ Hungary
}

Differentiation inhibiting activity/leukemia inhibitory factor (DIA/LIF) is a glycoprotein that controls differentiation of pluripotential stem cells. Alternative transcription generates both diffusible and matrixassociated forms of DIA/LIF. Transcriptional analysis using a sensitive ribonuclease protection assay revealed that the two messages are expressed independently, consistent with the proposition that the two forms of DIA/ LIF have distinct biological roles. DIA/LIF expression was found to be activated early during differentiation of embryonic stem (ES) cells, providing a mechanism for feedback regulation of stem cell renewal. Expression of DIA/LIF by mesenchymal cells was shown to be controlled in a paracrine manner by polypeptide regulatory factors. Specific expression of the two forms of DIA/LIF was also demonstrated in the egg cylinder-stage mouse embryo. The combination of cell type-specific and signal-specific regulation enables very precise control over DIA/LIF expression and may represent an important component of the regulatory networks that govern stem cell proliferation and differentiation during mammalian development.

[Key Words: Differentiation inhibiting activity; leukemia inhibitory factor; ES cells; growth factors; induction; gene expression]

Received July 9, 1990; revised version accepted October 15, 1990.

The development of the mammalian embryo is governed by interactions between different embryonic cell populations. This is manifest at the cellular level in the precise temporal and spatial control of proliferation, differentiation, and migration. It is becoming increasingly apparent that the coordination of such processes may be achieved largely via the action of a specific group of extracellular signaling molecules, developmental regulatory factors (for review, see Heath and Smith 1989). Although often initially characterized as growth factors, developmental regulatory factors are characteristically pleiotropic, may interact with one another synergistically or antagonistically, and can evoke diverse responses in different cell types (Sporn and Roberts 1988). The capacity of regulatory factors to act individually or in combination to orchestrate complex developmental processes is exemplified by the induction of mesoderm in animal pole explants of Xenopus laevis by basic fibroblast growth

Present addresses: ${ }^{5}$ Health Sciences Center, University of Calgary, Alberta T2N 4N1, Canada; 'Department of Biochemistry, University of Adelaide, Adelaide, South Australia 5001.

${ }^{7}$ Corresponding author. factor (bFGF) and XTC-MIF/activin A (Slack et al. 1987; Green et al. 1990; Smith et al. 1990).

The early mammalian embryo is, in most respects, experimentally inaccessible and therefore cannot readily be employed to detect and identify developmental regulatory factors directly. However, an appropriate assay system is provided by embryonic stem (ES) cell culture. ES cells are not transformed but established directly from pluripotential embryo cells (Evans and Kaufman 1981; Martin 1981) and, even after prolonged periods of culture, retain all the properties of such cells, including the capacity to form functional gametes (for review, see Robertson 1986). It is therefore reasonable to expect that factors expressed by, or acting on, ES cells will be involved in early embryonic development (Heath and Smith 1988). ES cell differentiation is controlled by the regulatory factor differentiation inhibiting activity (DIA) (Smith and Hooper 1987; Smith et al. 1988; Nichols et al. 1990). This is identical to the myeloid regulator leukemia inhibitory factor (LIF) (Hilton et al. 1988; Williams et al. 1988). DIA/LIF was originally characterized as a diffusible glycoprotein present in culture supernatants. It has now been demonstrated that DIA/LIF is also 
produced in a localized form that is immobilized via incorporation into the extracellular matrix (Rathjen et al. 1990|. The spatial diversity of DIA/LIF distribution arises from the modular organization of the DIA/LIF gene in which alternative first exons may be transcribed from different promoters. The production of the same regulatory factor in two forms is significant in that there are distinctive roles during development for diffusible and localized signaling molecules (Rathjen et al. 1990).

DIA/LIF inhibits the differentiation of ES cells and allows their propagation as pure populations of pluripotential stem cells. It also enables the derivation of ES cell lines in the absence of heterologous feeder cells ( $\mathrm{Ni}$ chols et al. 1990). DIA/LIF is thus implicated in the control of stem cell differentiation in the blastocyst and egg cylinder. The actions of DIA/LIF are probably not confined to the early embryo, however, but are also likely to extend to stem and progenitor cell populations in later development. This is suggested by analogy with other developmental regulatory factors that have multiple sites of action (Lehnert and Akhurst 1988; Heath and Smith 1989), by the diverse effects of DIA/LIF in vivo (Metcalf and Gearing 1989), and by specific actions of DIA/LIF in vitro, notably in hemopoietic (Hilton et al. 1988; Moreau et al. 1988; Leary et al. 1990) and osteogenic (Abe et al. 1986) systems.

To appreciate fully the potential functions of DIA/LIF it is necessary to define the conditions that determine its expression. Here, we report that (1) production of the alternative forms of DIA/LIF is developmentally programmed; (2) expression of DIA/LIF may be modulated by other bioregulatory factors; and (3) DIA/LIF is differentially expressed in the early embryo. These findings demonstrate that production of DIA/LIF is controlled very precisely and forms part of the interactive regulatory networks that preserve the essential balance between self-renewal and differentiation in stem cell populations.

\section{Results}

$D I A / L I F$ expression is induced on differentiation of ES cells

ES cells can be induced to undergo differentiation with high efficiency in monolayer culture by exposure to the chemical inducers retinoic acid (RA) (Smith and Hooper 1987; Heath and Smith 1988) or 3-methoxybenzamide (MBA) (Smith 1990). Cytoplasmic RNA from such differentiated cultures was analyzed for DIA/LIF transcription by Northern hybridization (Fig. 1). There was a significant increase in the specific $4.5-\mathrm{kb}$ DIA/LIF signal (Rathjen et al. 1990) in differentiated progeny relative to the stem cells. This effect was unlikely to be due to a direct effect of RA or MBA on DIA/LIF expression, as the inducers were removed from the culture $48 \mathrm{hr}$ prior to harvesting the cells.

The increase in steady-state mRNA levels was accompanied by acquisition of the ability to function as a

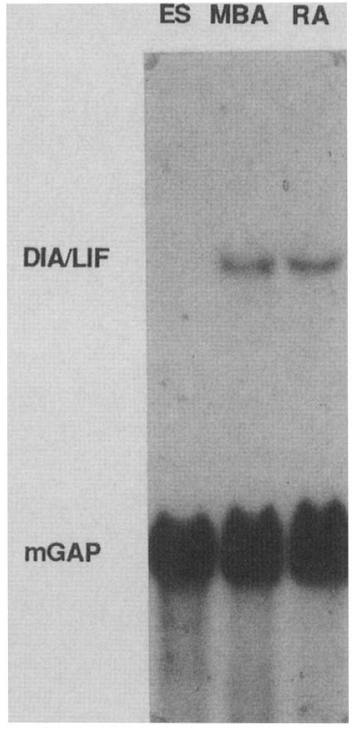

Figure 1. Northern hybridization of DIA/LIF transcription in undifferentiated and differentiated ES cells. Ten micrograms of cytoplasmic RNAs from CPI ES cells (ES), CP1 ES cells differentiated by exposure to all-trans-retinoic acid (RA), and CPI ES cells differentiated by exposure to 3-methoxybenzamide (MBA) were assayed for DIA/LIF expression by Northern hybridization. The DIA/LIF antisense RNA probe was derived from pDRI (Rathjen et al. 1990). RA and MBA were removed after 72 $\mathrm{hr}$, and differentiation was allowed to proceed for an additional 2 days. Oligolabeled murine GAP cDNA was used as a loading control.

feeder layer and support the growth of stem cell colonies when seeded with fresh ES cells (data not shown). This was due in part to secretion of DIA/LIF into the medium. The activity present in medium conditioned for 3 days by a confluent monolayer of MBA-treated ES cells was $10 \mathrm{U} / \mathrm{ml}$, which is $50 \%$ of that present in BRL cellconditioned medium prepared under the same conditions (Smith and Hooper 1987).

DIA/LIF exists in two forms, diffusible (D) and matrix-associated (M), which arise from alternative primary transcripts (Rathien et al. 1990). These two transcripts comigrate on agarose gels and consequently cannot be discriminated by Northern hybridization. Ribonuclease protection analysis was therefore employed to determine the relative levels of expression of both transcripts on stem cell differentiation. This analysis was applied to three independently isolated ES cell lines and to three lines of their tumorigenic counterparts, embryonal carcinoma (EC) cells (Fig. 2). DIA/LIF transcripts were expressed at very low levels compared with glyceraldehyde phosphate dehydrogenase $(\mathrm{GAP})$ mRNA $\{\sim 10-100,000-$ fold less abundant). Nonetheless, low but clearly detectable levels of the $M$ transcript were apparent in ES cells (see also Fig. 3). This finding contrasts with a report based on reverse transcription polymerase chain reaction (PCR; Conquet and Brulet 1990) in which it was 


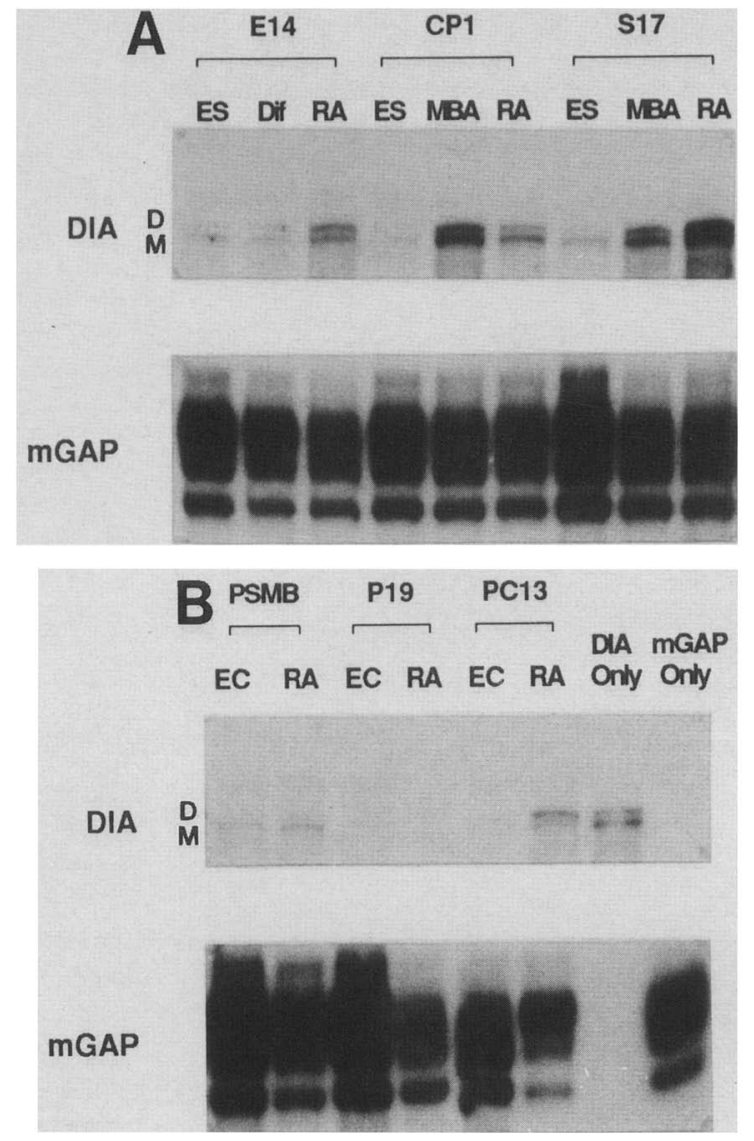

Figure 2. Ribonuclease protection analysis of DIA/LIF transcription in undifferentiated and differentiated ES and EC cells. Ribonuclease protection analysis was carried out on $15 \mu \mathrm{g}$ cytoplasmic RNA from E14, CPl, and S17 ES cell lines (ES), differentiated cells derived from these lines by plating at low density in the absence of DIA/LIF (Dif), or exposure to retinoic acid (RA) or 3-methoxybenzamide (MBA) $|A|$, and $15 \mu$ g cytoplasmic RNA from PSMB, P19, and PC13.5 EC cell lines (EC) and from the RA-differentiated derivatives of these lines (RA) $(B)$. RA was used at $10^{-5} \mathrm{M}$ to induce differentiation of PC13.5. Differentiation was allowed to proceed for 4 days $(C P 1, E 14$, and PSMB) or 5 days (S-17, P19, and PC13.5). In all cases, the differentiated populations were adjudged free of contaminating stem cells by morphological inspection. The antisense DIA/LIF RNA probe was synthesized by T7 polymerase transcription of HindIII-linearized pDRl (Rathjen et al. 1990), and the antisense mGAP probe was synthesized by SP6 polymerase transcription of BamHI-linearized pmGAP in B/S. The upper protected DIA/ LIF band corresponds to the $D$ transcript, and the lower band corresponds to the $\mathrm{M}$ transcript. Autoradiography was carried out for $3(A)$ or 6 days $(B)$.

stated that ES cells do not express DIA/LIF. A modest induction was observed on differentiation induced by withdrawal of DIA/LIF for $96 \mathrm{hr}$, whereas both transcripts were induced to relatively high levels on differentiation of ES cells in response to RA or MBA (Fig. 2A). The three EC lines investigated did not show elevated expression of DIA/LIF, indicating that autocrine production of DIA/LIF is not a general mechanism of transfor- mation in teratocarcinoma stem cells as proposed by Kola et al. (1990). RA induces differentiation of EC cells into various embryonic cell types, whose phenotype varies with the parental cell line (Strickland and Mahdavi 1978; Jetten et al. 1979; Rudnicki and McBurney 1987). The three lines used in this study produce morphologically distinct progeny, and these exhibited different patterns of DIA/LIF expression. PSMB and PC13.5 cells showed moderate inductions of the $M$ and $D$ transcripts, respectively, whereas P19 displayed no detectable increase in either. Thus, expression of the two forms of DIA/LIF can be independently regulated during cellular differentiation.

\section{Time course of DIA/LIF induction during differentiation-a model for stem cell renewal}

The finding that DIA/LIF expression is activated in the differentiated progeny of ES cells prompted an examination of the time course of induction. DIA/LIF expression was monitored in ES cells induced to differentiate by withdrawal of DIA/LIF (Fig. 3). Transcript levels were found to be enhanced after $24 \mathrm{hr}$, reach maximal levels at $72 \mathrm{hr}$, and decline. Only low levels $(<2 \mathrm{U} / \mathrm{ml})$ of biological activity could be detected in supernatants harvested from such cultures. However, both $D$ and $M$ DIA/LIF were produced in sufficient quantities to sustain stem cell propagation. This was shown in two ways. First, a sensitive transfilter coculture assay was employed for the detection of diffusible DIA/LIF (Rathjen et al. 1990|. A microporous membrane was used to separate ES cells, plated at clonal density, from an underlying monolayer culture. Pure stem cell colonies or colonies containing significant numbers of stem cells were obtained on filters seeded after differentiation of the underlying culture had been allowed to proceed for $48-72$ hr. This confirmed that low levels of diffusible DIA/LIF are produced by recently differentiated ES cells. The second demonstration that functional DIA/LIF is produced during ES cell differentiation was provided by the observation of incomplete differentiation on withdrawal of DIA/LIF from high-density cultures. Differentiation of entire ES cell populations was only obtained if the cells were seeded at low density, $<2 \times 10^{3}$ cells $/ \mathrm{cm}^{2}$. At higher densities the cells initially appeared to undergo fairly homogeneous morphological differentiation, but after 3-5 days nests of stem cells could be detected and these subsequently proliferated into macroscopic colonies (Fig. 4) that exhibited characteristic ES cell morphology and expressed the stem cell-specific marker SSEA-1 (data not shown). This phenomenon was observed with four independent ES cell lines and therefore seemed unlikely to arise by selection for a subpopulation of differentiation-defective variants. This possibility was directly tested by picking two stem cell colonies from a differentiated culture, expanding them in the presence of DIA/LIF, and replating at clonal density in a differentiation assay (Table 1). Both clones showed comparable plating efficiency to the parental line and like- 


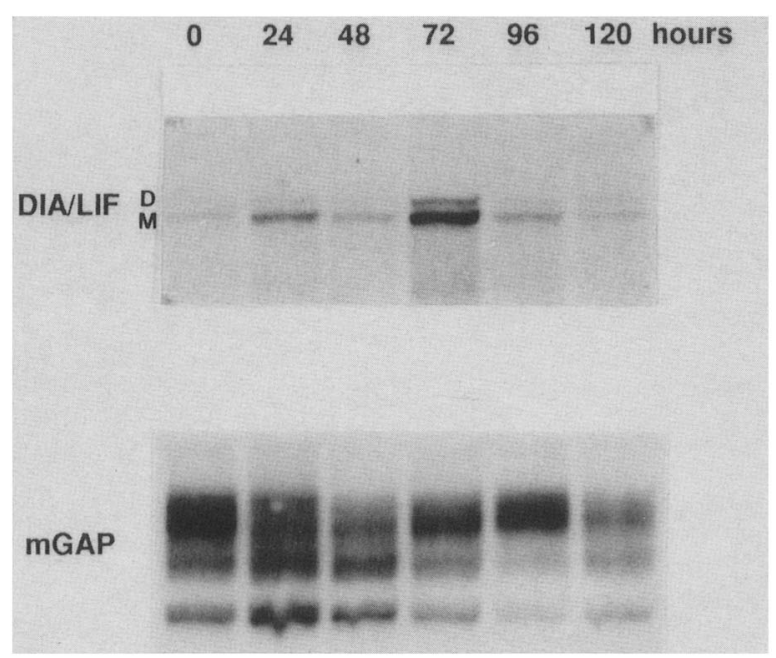

Figure 3. Time course of DIA/LIF expression during differentiation of ES cells following withdrawal of DIA/LIF. Duplicate cultures of S-17 ES cells were cultured for $24 \mathrm{hr}$ in the presence of DIA/LIF. DIA/LIF was then withdrawn from the medium 10 hr). Cultures were harvested at 24-hr intervals for a period of 5 days. Fifteen micrograms of cytoplasmic RNA from each culture was assayed for DIA/LIF expression, as described in the legend to Fig. 2. (Top) Numbers refer to hours elapsed following withdrawal of DIA/LIF.

wise formed $>90 \%$ pure stem cell colonies in the presence of DIA/LIF. They produced differentiated colonies in the absence of DIA/LIF with the same efficiency as the parental cells. Therefore, these cells were not DIA/ LIF-independent variants but were representative of the original ES cell population. These observations indicate that the early activation of DIA/LIF expression during stem cell differentiation provides a mechanism whereby differentiation can proceed without exhaustion of the stem cell pool.

\section{Modulation of DIA/LIF expression by regulatory factors}

An important component of the interactive signaling network provided by developmental regulatory factors is the ability of particular regulatory factors to modulate

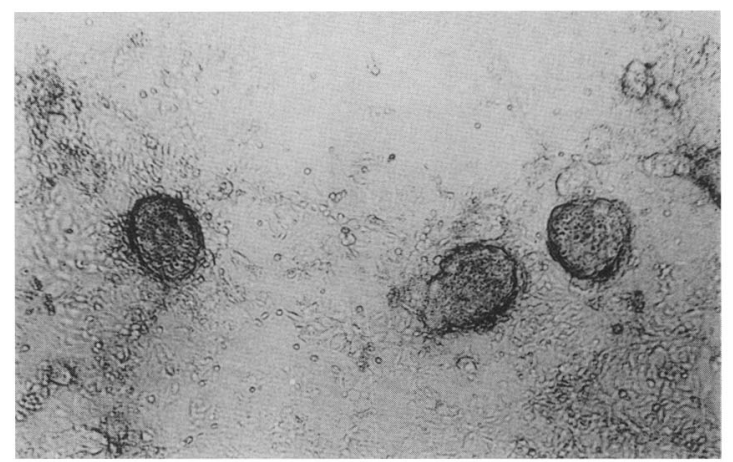

Figure 4. Photomicrograph of stem cell renewal during differentiation of ES cells. S-17 ES cells were plated at $2 \times 10^{4}$ cells/ $\mathrm{cm}^{2}$ and cultured for 6 days in the absence of DIA/LIF. Magnification, $100 \times$.
Table 1. Differentiation of ES cells and clones isolated following stem cell renewal

\begin{tabular}{lccr}
\hline & \multicolumn{3}{c}{ Percentage differentiated colonies } \\
\cline { 2 - 4 } & $\mathrm{S}-17$ & $\mathrm{~S}-17 \mathrm{~d} 1$ & $\mathrm{~S}-17 \mathrm{~d} 2$ \\
\hline + DIA/LIF & 5.4 & 5.2 & 7.4 \\
-DIA/LIF & 93.4 & 92.0 & 93.6 \\
\hline
\end{tabular}

S-17 ES cells were plated at $10^{4}$ cells $/ \mathrm{cm}^{2}$ in the absence of DIA/LIF and cultured for 6 days. Regenerated stem cell colonies were picked and expanded into cell lines (S-17dl and S-17d2) in the presence of DIA/LIF. Differentiation assays were performed by plating cells at clonal density and culturing for 6 days in the presence or absence of DIA/LIF. The proportion of differentiated colonies was determined by morphological inspection following staining with Leishman's (Smith and Hooper 1987). Five hundred colonies were scored on each dish.

the expression of other bioregulators. Accordingly, the response of DIA/LIF expression to a variety of regulatory factors was investigated (Fig. 5). In quiescent MRC-5 human embryonic lung fibroblasts (Fig. 5A), DIA/LIF transcripts were induced at low levels by stimulation with serum and at higher levels by phorbol esters or purified growth factors. This induction was predominantly of DIA/LIF-D, as the $M$ transcript was barely detectable in these cells. Induction of DIA/LIF-D transcripts was reflected in the appearance of biologically active DIA/ LIF-D in culture supernatants from stimulated cells (Fig. 5C). The DIA/LIF-D transcript was also inducible in mouse embryo fibroblast cell lines Swiss 3T3 data not shown) and C3H 10T1/2 (Fig. 5B). The mouse fibroblasts also expressed DIA/LIF-M. In some cases [bFGF and interleukin- $1 \alpha(\mathrm{Il}-1 \alpha)]$, the two transcripts were equally responsive, but in others [transforming growth factor- $\beta$ [TGF- $\beta$ )] the increase in DIA/LIF-D expression was significantly greater than that in DIA/LIF-M. Therefore, expression of the two forms of DIA/LIF can be differentially responsive to other developmental regulatory factors.

Members of the TGF- $\beta$ family were particularly potent inducers of DIA/LIF transcription in C3H 10T1/2 fibroblasts, and expression of DIA/LIF-D could be further enhanced by treatment of quiescent cells with TGF- $\beta$ in combination with bFGF (Fig. 5B). In contrast, the glucocorticoid dexamethasone prevented induction of DIA/LIF by Il- $1 \alpha$, though not by bFGF. Thus, both the form and extent of DIA/LIF expression by a cell are determined by the total input of regulatory signals. The difference in regulation of DIA/LIF transcription between MRC-5 and C3H 10T1/2 cells in response to particular developmental regulatory factors, notably epidermal growth factor (EGF) and TGF- $\beta$, demonstrates the importance of cellular phenotype in the control of DIA/LIF expression. This is also illustrated by the relatively high levels of DIA/LIF transcripts found in differentiated ES cells obtained by RA treatment. In these cells expression of DIA/LIF was constitutive and apparently unaffected by the presence or absence of other developmental regulatory factors (Fig. $5 \mathrm{D})$. The contrasting very low level of DIA/LIF expression observed in undif- 

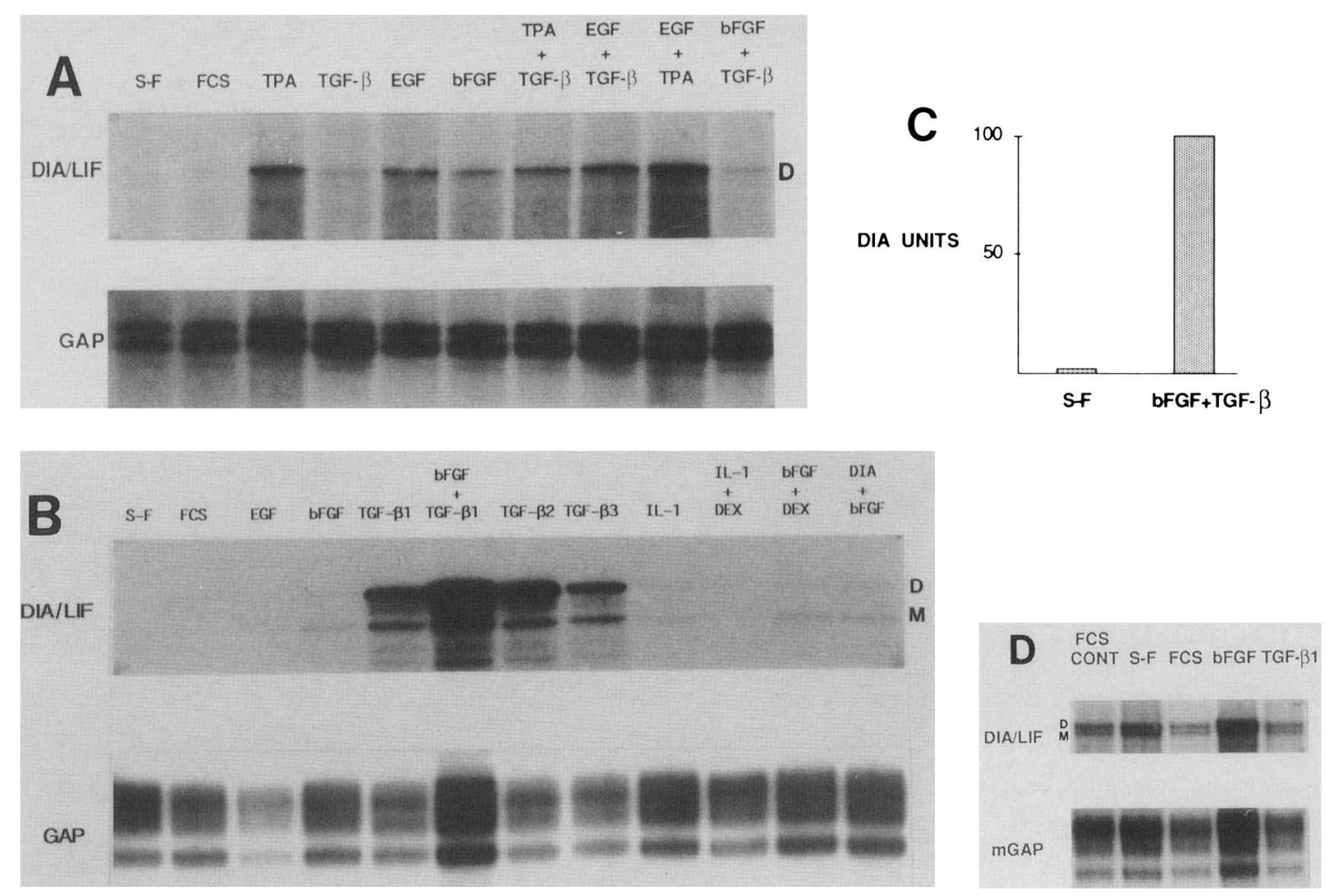

Figure 5. Modulation of DIA/LIF transcription by regulatory factors. $(A)$ Duplicate cultures of quiescent MRC-5 human fibroblasts were left untreated (S-F) or stimulated by the addition of $10 \%$ fetal calf serum, $10 \mathrm{nM} \mathrm{TPA}, 1 \mathrm{ng} / \mathrm{ml} \mathrm{TGF}-\beta_{1}, 10 \mathrm{ng} / \mathrm{ml} \mathrm{EGF,} 5 \mathrm{ng} / \mathrm{ml}$ bFGF, or combinations of these to the culture medium. Cells were harvested $12 \mathrm{hr}$ after stimulation, and $15 \mu \mathrm{g}$ cytoplasmic RNA was analyzed for DIA/LIF transcription by ribonuclease protection. The antisense human DIA/LIF probe was synthesized by T7 polymerase transcription of HindIII-linearized HpGEMl. The DIA/LIF band corresponds to the human DIA/LIF-D transcript. The protected GAP bands differ as expected from those observed in murine samples (see Materials and methods). (B) Duplicate cultures of quiescent $\mathrm{C} 3 \mathrm{H} 10 \mathrm{Tl} / 2$ murine fibroblasts were left untreated $|\mathrm{S}-\mathrm{F}\rangle$ or stimulated by the addition of $10 \%$ fetal calf senum, $10 \mathrm{ng} / \mathrm{ml}$ EGF, $5 \mathrm{ng} / \mathrm{ml}$ bFGF, $1 \mathrm{ng} / \mathrm{ml} \mathrm{TGF}-\beta_{1}, 1 \mathrm{ng} / \mathrm{ml} \mathrm{TGF}-\beta_{2}, 1 \mathrm{ng} / \mathrm{ml} \mathrm{TGF}-\mu_{3}, 10 \mathrm{U} / \mathrm{ml} \mathrm{Il-} 1 \alpha, 10^{-8} \mathrm{M}$ dexamethasone (DEX), or combinations of these to the culture medium. Cells were harvested $6 \mathrm{hr}$ after stimulation, and $5 \mu \mathrm{g}$ cytoplasmic RNA was assayed for DIA/LIF expression by ribonuclease protection. The short antisense DIA/LIF probe was synthesized by T7 polymerase transcription of $H i n d I I I-$ linearized pDR2 (Rathjen et al. 1990). The upper band corresponds to the DIA/LIF-D transcript; the lower band corresponds to the DIA/LIF-M transcript. (C) MRC-5 cells were quiesced as described above. Media were replaced after 24 hr with defined medium or with defined medium containing bFGF $(5 \mathrm{ng} / \mathrm{ml})$ and TGF- $\beta_{1}(1 \mathrm{ng} / \mathrm{ml})$ and incubated for $48 \mathrm{hr}$. Conditioned media were filtered $(0.4$ $\mu \mathrm{m}$ ) and assayed for differentiation-inhibiting activity. (D) CP1 ES cells were induced to differentiate by exposure to RA. After differentiation had proceeded for 4 days, cultures were left in serum-containing medium (FCS CONT), or transferred into serum-free medium for $24 \mathrm{hr}$. The serum-free cultures were left untreated (S-F) or stimulated by the addition of $10 \%$ fetal calf serum, $5 \mathrm{ng} / \mathrm{ml}$ bFGF, or $1 \mathrm{ng} / \mathrm{ml} \mathrm{TGF}-\beta_{1}$. Cells were harvested $6 \mathrm{hr}$ after stimulation, and $5 \mu \mathrm{g}$ cytoplasmic RNA was assayed for DIA/LIF expression by ribonuclease protection as described in the legend to Fig. 2 .

ferentiated ES cells was also unaffected by either TGF- $\beta$ or bFGF (data not shown). These findings show that expression of both forms of DIA/LIF, particularly of DIA/ LIF-D, may be influenced by exposure to combinations of specific developmental regulatory factors but that such effects are dependent on cellular context.

The activation of DIA/LIF expression in embryonic fibroblasts was detectable within $60 \mathrm{~min}$ on stimulation with bFGF (Fig. 6A) and within $30 \mathrm{~min}$ on stimulation with TGF- $\beta$ (Fig. $6 \mathrm{~B}$ ). The rapid kinetics of this response indicated that DIA/LIF is a primary response gene. The induction of DIA/LIF thus appears to be a direct effect that is not mediated via induction of other gene products. This was confirmed by the finding that induction proceeds in the presence of protein synthesis inhibitors (Fig. 6C). Indeed, the response to bFGF was en- hanced in the presence of cycloheximide, as reported for other rapidly inducible genes (Greenberg et al. 1986). Moreover, protein synthesis inhibitors alone could induce accumulation of DIA/LIF transcripts (Fig. $6 \mathrm{C}$ ), as described for well-characterized early genes such as c-fos and c-myc (Amendral et al. 1988). However, there is no obligatory association between the activation of mitogenic signaling pathways and induction of DIA/LIF, as neither TPA (data not shown) nor EGF (Fig. 5B) induced DIA/LIF transcription in C3H 10T1/2 fibroblasts, despite being potent inducers of transcription of other early genes in these cells (Mahadevan et al. 1990).

\section{Paracrine induction of DIA/LIF expression by ES cells}

The finding that DIA/LIF transcription can be regulated 

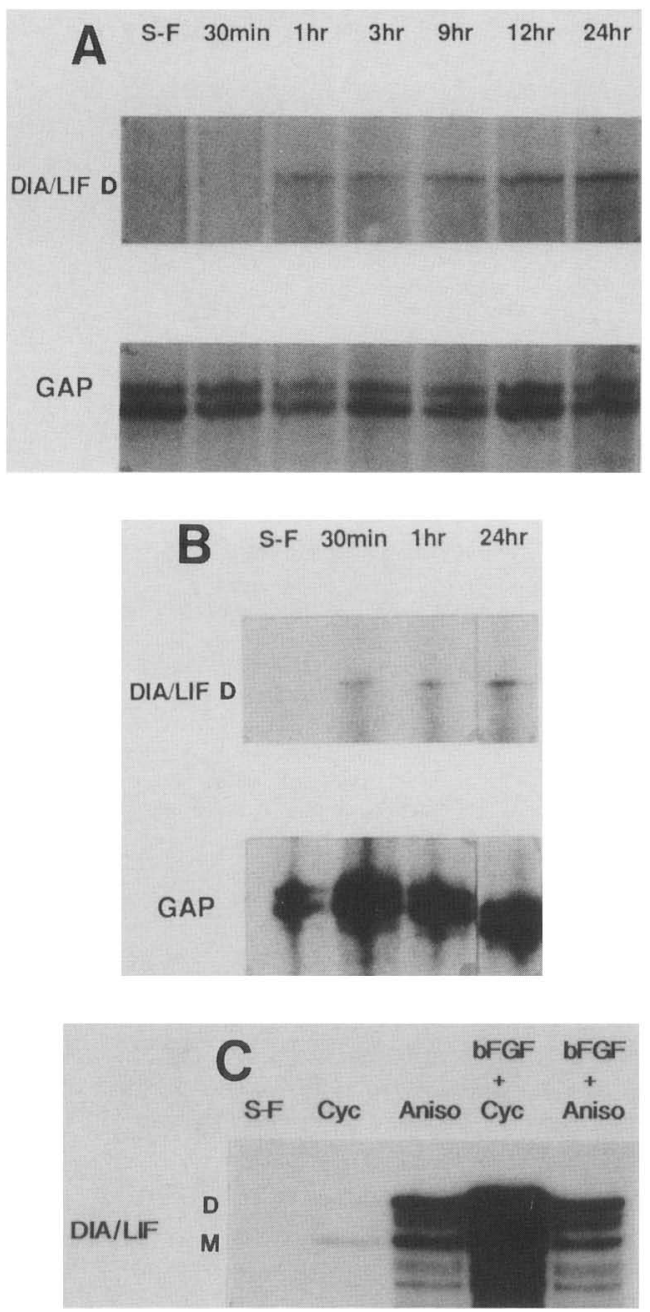

Figure 6. Induction of DIA/LIF expression by regulatory factors is a primary response. (A) Time course of DIA/LIF transcription in MRC- 5 human fibroblasts stimulated with $5 \mathrm{ng} / \mathrm{ml}$ bFGF. Duplicate quiescent cultures were harvested 0.5, 1, 3, 9, 12 , and $24 \mathrm{hr}$ after stimulation, and $10 \mu \mathrm{g}$ cytoplasmic RNA was assayed for DIA/LIF expression as described in the legend to Fig 5A. $(B)$ Time course of DIA/LIF transcription in MRC-5 fibroblasts stimulated with TGF- $\beta_{1}$. Cultures were harvested $0.5,1$, and $24 \mathrm{hr}$ after stimulation and assayed for DIA/LIF expression as described in the legend to Fig. 5A. (C) Induction of DIA/LIF expression by protein synthesis inhibitors. Quiescent C3H 10T1/2 murine fibroblasts were treated with $10 \mu \mathrm{g} / \mathrm{ml} \mathrm{cy}$ cloheximide (Cyc), $10 \mu \mathrm{g} / \mathrm{ml}$ anisomycin (Aniso), $5 \mathrm{ng} / \mathrm{ml}$ bFGF, or combinations of these. Cells were harvested after $6 \mathrm{hr}$ and assayed for DIA/LIF expression as described in the legend to Fig. 5B.

by other developmental regulatory factors suggested that signals of this nature between neighboring cells might be used to control the local expression of DIA/LIF. Interactions between ES cells and 10T1/2 feeder layers can be studied in vitro under controlled conditions. DIA/LIF activity deposited in the extracellular matrix of $\mathrm{C} 3 \mathrm{H}$ $10 \mathrm{~T} 1 / 2$ feeder cells inhibits the differentiation of pluripotential ES cells but is insufficient to suppress differen- tiation completely for extended periods of culture (Rathien et al. 1990). Therefore, the possibility that a secreted signal might be used in this system to elevate the levels of DIA/LIF protein available to the ES cells during coculture was investigated.

The low levels of DIA/LIF transcripts present in mRNA from $10 \mathrm{~T} 1 / 2$ feeders or ES cells were significantly elevated in mRNA prepared from a coculture consisting of feeders seeded with ES cells (Fig. 7A). This effect was reproduced by incubation of the feeders with ES cell-conditioned medium but not by incubation of ES cells with feeder-conditioned medium. Therefore, ES cells secrete a factor that stimulates expression of DIA/ LIF, and particularly of DIA/LIF-D, by $10 \mathrm{Tl} / 2$ fibroblasts. This factor was detected in medium conditioned by ES cells in both the presence and absence of serum. The nature of this factor was investigated by fractionation of serum-free ES cell-conditioned medium via heparin-Sepharose affinity chromatography. The ES cell activity responsible for induction of DIA/LIF adsorbed to heparin with high affinity (Fig. 7B). It coeluted with a heparin-binding growth factor (HBGF) that was a potent mitogen for $10 \mathrm{~T} 1 / 2$ cells (Fig. 7C). The prototypic member of the HBGF family is bFGF (Gospodarowicz 1974), which induces a similar pattern of DIA/LIF expression in $10 \mathrm{~T} 1 / 2$ fibroblasts (Fig. $5 \mathrm{~B}$ ). It is therefore probable that the HBGF secreted by ES cells was responsible for the induction of DIA/LIF expression in 10T1/2 feeder cells. This result demonstrates production of a functional developmental regulatory factor by ES cells that can act both as a mitogen and as an inducer of DIA/ LIF in mesenchymal cells.

\section{DIA/LIF transcripts are expressed in the 6.5-day mouse egg cylinder}

The preceding data on regulation of DIA/LIF expression in vitro have important implications for the potential role(s) of this factor in vivo. As a first stage in the analysis of DIA/LIF expression in vivo, the distribution of transcripts in the egg cylinder-stage mouse embryo has been investigated. ES cells most closely resemble the pluripotential primitive ectoderm cells of the early postimplantation embryo (Evans and Kaufman 1983). By 6.5 days postcoitum (the first time at which it is really feasible to extract sufficient RNA for this type of analysis) this population begins to undergo localized differentiation into mesoderm, a process that proceeds progressively during the succeeding $24 \mathrm{hr}$. RNA was prepared from embryos at these stages of development for determination of DIA/LIF expression by RNase protection (Fig. 8). Transcripts were not detectable in decidua at either stage, nor in the 7.5-day embryonic region, and only very low levels of the $M$ transcript were detected in the 6.5-day embryonic region. However, both D and $M$ transcripts were found at relatively high levels in the extraembryonic region, with the $\mathrm{D}$ form approximately fivefold more abundant than the $\mathrm{M}$ form. Expression of both transcripts was greater at 6.5 days than at 7.5 days, with the $M$ transcript scarcely detectable at the latter 


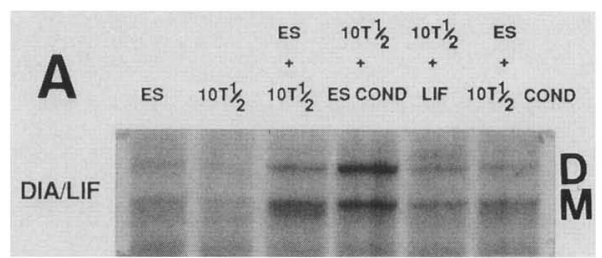

Figure 7. Induction of DIA/LIF expression in $\mathrm{C} 3 \mathrm{H} 10 \mathrm{~T} 1 / 2$ feeder cells by a HBGF secreted by ES cells. $(A)$ Ribonuclease protection analysis of DIA/LIF transcripts expressed in CP1 ES cells and C3H $10 \mathrm{~T} 1 / 2$ feeder cells cultured separately, in combination, or in the presence of medium conditioned by preincubation with the heterologous cell type. Incubations were continued for $48 \mathrm{hr}$ before harvesting. $(B)$ Ribonuclease protection analysis of DIA/LIF transcripts expressed by $\mathrm{C} 3 \mathrm{H} 10 \mathrm{~T} 1 / 2$ feeder cells in response to serum-free ES cell-conditioned medium fractionated by heparin-Sepharose affinity chromatography. Incubations were continued for $6 \mathrm{hr}$ before harvesting. Feeder layers in serum-containing medium were used 3 days after preparation in both $A$ and $B$. Ribonuclease protections were performed as in Fig. $5 \mathrm{~B}$ on $5 \mu \mathrm{g}$ cytoplasmic RNA. $(C)$ Mitogenic activity on $\mathrm{C} 3 \mathrm{H} 10 \mathrm{~T} 1 / 2$ fibroblasts of ES cell-conditioned medium fractionated by heparin-Sepharose chromatography. Mean counts per minute obtained in the absence of stimulation were subtracted from all values.

stage. These data establish that both DIA/LIF-D and DIA/LIF-M are expressed during early embryogenesis. Moreover, there is both temporal and tissue-specific regulation of expression of the two transcripts.

\section{Discussion}

DIA/LIF is a developmental regulatory factor that specifically inhibits the differentiation of pluripotential early embryo stem cells in culture and is a strong candidate as a regulatory factor for embryo stem cells in vivo. DIA/ LIF has a variety of other activities, including effects on primitive hemopoietic cells (Leary et al. 1990) and leukemic cell lines (Hilton et al. 1988; Moreau et al. 1988), stimulation of bone resorption (Abe et al. 1986) and bone formation (Metcalf and Gearing 1989), inhibition of adipogenesis (Mori et al. 1989), induction of the acute phase response in hepatocytes (Baumann and Wong 1989), and regulation of neuronal phenotype (Yamamori et al. 1989|. DIA/LIF is produced in two forms, freely D and $M$, generated by alternative promoter usage (Rathjen et al. 1990). The physiological significance of the variant forms of DIA/LIF presumably resides in their separate physical localization, which is potentially of great importance for the spatial control of stem cell self-renewal and differentiation throughout development. It is therefore essential to determine how expression of the two forms of DIA/LIF is regulated.

Analysis of DIA/LIF expression on differentiation of ES and EC cells revealed several interesting features. First, it is apparent that undifferentiated ES cells express low levels of DIA/LIF. This suggests the possibility that DIA/LIF may function in an autocrine manner during development of the inner cell mass (ICM)/primitive ectoderm. Second, the level of expression on differentiation is dependent on the particular developmental program. Thus, although RA- or MBA-induced ES cells ex- pressed high levels of DIA/LIF, this was not an obligatory fate of differentiated stem cell progeny. Third, the relative expression of the two forms of DIA/LIF varied with differentiated cell phenotype. Thus, the developmental regulation of the two promoters and/or processing of the two primary transcripts is autonomous. It is therefore probable that different forms of DIA/LIF are produced in different compartments of the embryo.

The demonstration of enhanced DIA/LIF expression in differentiating ES cells, coupled with the observation that ES cell differentiation is density-dependent, sug-

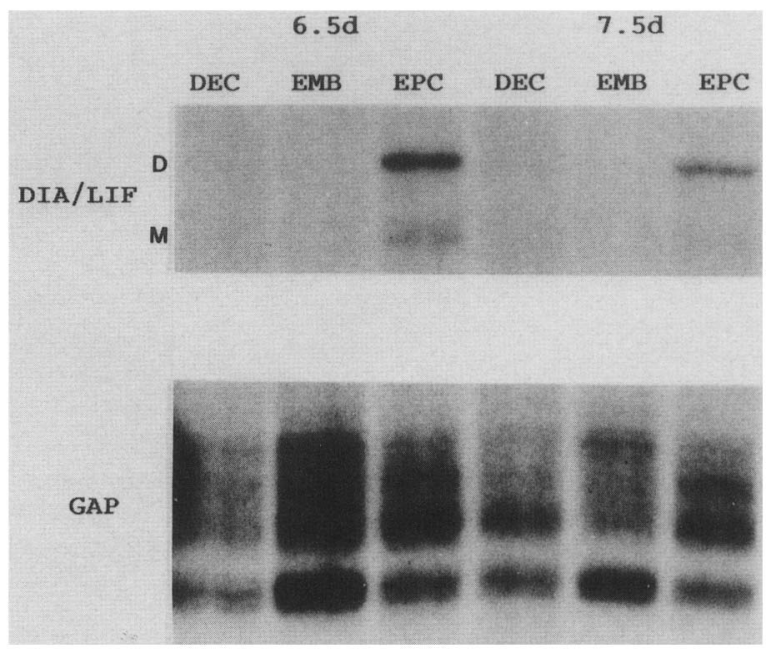

Figure 8. Expression of DIA/LIF transcripts in the mouse egg cylinder. Ribonuclease protection analysis of DIA/LIF transcripts in decidua (DEC) and embryonic (EMB) and extraembryonic (EPC) regions of the mouse egg cylinder at 6.5 and 7.5 days postcoitum. One microgram of total RNA was analyzed using the short DIA/LIF probe, as described in the legend to Fig. 5(B). 
gests a feedback mechanism for stem cell renewal accompanying differentiation (Fig. 9). The essential feature of this model is that early activation of DIA/LIF expression by differentiated progeny results in the inhibition of subsequent differentiation. Provided that the initial differentiation does not occur uniformly, self-renewal will proceed in a localized manner. This occurred readily in asynchronous populations of ES cells in vitro. It is also noteworthy that in primary teratocarcinomas small nests of EC stem cells are generally surrounded by differentiated tissue. This may reflect a parallel dependence of the tumor stem cells on DIA/LIF produced by their differentiated progeny. Differentiation-dependent self-renewal could be of crucial importance in the early mammalian embryo where a series of differentiation events are accompanied by expansion of the pluripotential stem cell pool prior to gastrulation. The maintenance of pluripotential stem cells from both pre- and postimplantation embryos appears to be dependent on proximity to differentiated cell types (Hogan and Tilly 1977; Rossant and Ofer 1977; Gardner 1985). Similar mechanisms may be operative on other stem cell populations during both embryonic development and adult life. It is possible that the production of localized forms of DIA/LIF or analogous stem cell regulators by immediate differentiated progeny may be the essential feature of those specialized microenvironments (Schofield 1978) required for stem cell persistence, for example, in the gut and bone marrow.

In addition to being developmentally regulated, the expression of DIA/LIF is modulated by other bioregulatory molecules. The extent and form of regulation are highly specific, depending on both the phenotype of the responsive cells and the nature of the agonist. Thus, the efficacy of different inducers differed between MRC-5 and C3H 10T1/2 fibroblasts, and only DIA/LIF-D appeared to be inducible in the former whereas both transcripts could be induced in C3H 10T1/2 cells. Furthermore, the relative induction of the two transcripts in $\mathrm{C} 3 \mathrm{H} \mathrm{10Tl} / 2$ cells depended on the identity of the inducing agent. Even the superficially similar effects of bFGF and Il- $l \alpha$ were mediated by separate mechanisms because they exhibited differential suppression by dexamethasone. The inhibitory effect of dexamethasone is significant in that it establishes the existence of nega-

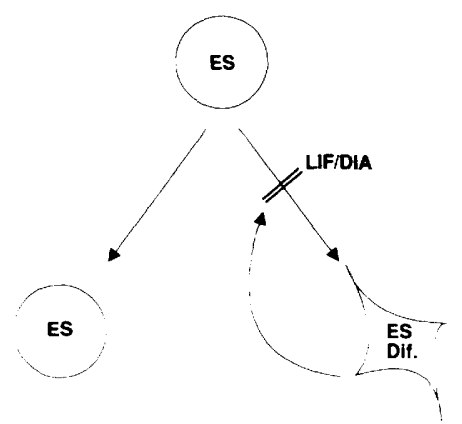

Figure 9. Feedback regulation of stem cell renewal. tive regulators of DIA/LIF. Such molecules are likely to play a vital role in restricting the expression of DIA/LIF to appropriate physiological situations. These findings indicate that precise regulation of the expression of diffusible and localized DIA/LIF can be achieved by the combination of a variety of specific inducers and repressors coupled with independent developmental programming of the two DIA/LIF promoters. Fine control over production of DIA/LIF is essential for such a potent stem cell factor, deregulated expression of which has multiple pathological consequences (Metcalf and Gearing 1989|. Similar control networks may be anticipated for other developmental regulatory factors.

It is striking that DIA/LIF-D is directly inducible in mesenchymal cells by several developmental regulatory factors, including members of the TGF- $\beta$ family. Signaling polypeptides, especially the TGF- $\beta$ family, have been implicated in regenerative processes associated with wounding and trauma (Roberts et al. 1986). The production of diffusible DIA/LIF may be involved in the essential activation of progenitor cells under such conditions. This is an important area of future investigation. The implication that DIA/LIF may be a mediator of some of the pleiotropic effects of TGF- $\beta$ and other regulatory factors is also significant in a developmental context. The recent report that lipoprotein lipase inhibitor, which inhibits the adipogenic conversion of preadipocytes, is apparently identical to DIA/LIF (Mori et al. 1989 ) indicates that the antiadipogenic effect of TGF- $\beta$ (Ignotz and Massagué 1985) could be mediated via DIA/ LIF. Moreover, the induction of adipogenesis by corticosteroids (Rubin et al. 1978) may be partly due to their suppression of DIA/LIF expression. DIA/LIF also has osteogenic activities (Abe et al. 1986; Metcalf and Gearing 1989 ) and therefore might be an intermediary in the activation of periostal mesenchyme by TGF- $\beta$ (Joyce et al. 1990|. Consistent with this, we have found that DIA/LIF expression is induced in primary cultures of human osteoblasts by several bone-active cytokines, including TGF- $\beta$ (D.B. Evans, P.D. Rathjen, and A.G. Smith, in prep.). It will be interesting to determine whether DIA/ LIF is also active on other progenitor cell populations such as myoblasts and prokeratinocytes that are regulated by TGF- $\beta$ (Massagúe et al. 1986; Shipley et al. 1986).

The potential functional significance of modulation of DIA/LIF expression by other regulatory factors is illustrated by the induction of DIA/LIF in feeder cells. ES cells are initially supported by $\mathrm{C} 3 \mathrm{H} 10 \mathrm{Tl} / 2$ feeder layers due to deposition of DIA/LIF-M in the extracellular matrix (Rathjen et al. 1990). The amount of DIA/LIF-M is insufficient, however, to sustain growth to high density without appreciable differentiation. Such differentiation does not occur on intact feeder layers due to the induction of DIA/LIF expression in the feeder cells, a process that is mediated by secretion of a HBGF by the ES cells. The reciprocal interaction between ES and feeder cells may mirror events in the early embryo where pluripotential stem cells could ensure their own expansion in analogous fashion. This situation may also be recapitu- 
lated for expanding stem cell populations in later development.

Finally, ribonuclease protection assays have been employed to demonstrate unambiguously regulated expression of DIA/LIF transcripts in the early mouse conceptus (Fig. 8). It is striking that the major site of expression is in the extraembryonic portion of the egg cylinder, with only very low levels of the $M$ transcript detectable in the embryonic region at 6.5 days. Thus, transcription of DIA/LIF is differentially controlled in different compartments of the mouse embryo. However, further investigation is necessary to localize sites of synthesis to particular cell types. Expression of DIA/LIF in the extraembryonic half of the egg cylinder is suggestive of a paracrine interaction between the primitive ectoderm and the extraembryonic ectoderm/ectoplacental cone (EPC). However, it may also point to a role for DIA/LIF in maintenance of extraembryonic progenitor cells and/ or in induction of the decidua.

The studies presented in this paper indicate that expression of the stem cell regulatory factor DIA/LIF is an integral part of a complex regulatory network. Three key features have emerged: (1) Differentially localized forms of DIA/LIF are differentially expressed by different embryonic cell types, (2) activation of DIA/LIF expression on differentiation ensures stem cell renewal, and $|3|$ modulation of DIA/LIF expression by other regulatory factors enables precise paracrine regulation of stem cells. These findings provide a firm basis for the analysis of DIA/LIF expression and function in vivo. They also illustrate some principles of interactive control networks that may be of general significance in embryonic development.

\section{Materials and methods}

Cell culture and biological assays

Cell lines, tissue culture, and bioassay of DIA/LIF activity were as described by Rathjen et al. (1990). The ES cell lines employed, CP1, S17, CCE, and E14, all contribute extensively to chimeras in our hands, though to date only E14 has been transmitted through the germ line. The EC cell lines PC13.5 (Hooper and Slack 1977), P19 (McBurney and Rogers 1982), and PSMB (Lovell-Badge and Evans 1980) have been described elsewhere.

Differentiation was induced by culture in the absence of DIA/LIF, by exposure to all-trans-RA (at a final concentration of $10^{-6} \mathrm{M}$ unless otherwise specified) for $72 \mathrm{hr}$ in the absence of DIA/LIF or by exposure to $8 \mathrm{mM}$ MBA for $72 \mathrm{hr}$ in the presence of DIA/LIF. Cells were cultured for an additional 24 or $48 \mathrm{hr}$ in the absence of chemical inducer prior to harvesting for RNA preparation.

Transfilter assays were carried out using transparent microporous $(0.4 \mu \mathrm{m}$ pore size) inserts (Transwell) as described previously (Rathjen et al. 1990). ES cells were seeded into 6-well plates at a density of $5 \times 10^{3}$ cells per well in medium supplemented with DIA/LIF. Cells were cultured for an additional 96 $\mathrm{hr}$, during which period DIA/LIF was withdrawn from duplicate wells at 24-hr intervals, that is, cultures were allowed to differentiate for 24, 48, 72, or $96 \mathrm{hr}$. Control wells were maintained in DIA/LIF throughout. At the end of this period, all wells were changed to media without DIA/LIF, and membrane inserts were introduced. ES cells (500/well) were seeded onto each filter and cultured for $96 \mathrm{hr}$ before fixing and staining with crystal violet for assessment of morphological differentiation (Smith and Hooper 1987).

The effects of regulatory factors were investigated in cells that had been made quiescent by incubation at confluence for $24 \mathrm{hr}$ in basal medium supplemented with $10 \mathrm{mM}$ HEPES, $10^{-4}$ M 2-mercaptoethanol, $5 \mu \mathrm{g} / \mathrm{ml}$ iron-saturated transferrin, 1 $\mu \mathrm{g} / \mathrm{ml}$ insulin, and $3 \mathrm{nM}$ sodium selenite. Purified growth factors were purchased from $R$ and D systems (bFGF, TGF- $\beta_{1}$ and TGF- $\beta_{2}$ ) and Boehringer (Il-1 $\left.\alpha\right)$. Murine EGF was generously provided by George Panayotou, (Ludwig Institute, London), and TGF- $\beta_{3}$ was a gift from Peter ten Dijke (Oncogene Science). Mitogenic assays were performed by determination of $\left[{ }^{3} \mathrm{H}\right]$ thymidine incorporation in quiescent $\mathrm{C} 3 \mathrm{H} 10 \mathrm{~T} 1 / 2$ fibroblasts (Heath 19871 .

\section{Preparation of embryonic RNA}

Embryos were obtained from timed matings of strain MFl mice. Egg cylinders were isolated using siliconized glass needles to dissect off Reichert's membrane. The extraembryonic region was then separated from the embryonic (EMB) region at the point of insertion of Reichert's membrane by gentle slicing with the glass needles. After rinsing in PBS, pooled EPCs and pooled EMB regions were frozen by immersion in liquid nitrogen and stored at $-80^{\circ} \mathrm{C}$. When $\sim 250$ of each had been collected, they were thawed rapidly and lysed by sonication in $3 \mathrm{M} \mathrm{LiCl} / 6 \mathrm{M}$ urea. Decidua were homogenized directly using an Ultra Turrax. Total RNA was then prepared by the method of Auffray and Rougenon (1980).

\section{RNA analysis}

Preparation of cytoplasmic RNA from cultured cells and analysis by Northern hybridization and ribonuclease protection assays were carried out as described (Rathien et al. 1990). The results shown are representative of at least two independent analyses, with the exceptions of the embryonic and S-17 time course RNAs, which were not duplicated. Two different riboprobes specific for murine DIA/LIF were used in the course of this analysis. The antisense probe obtained by transcription of pDRI (Rathjen et al. 1990) contains the murine DIA/LIF open reading frame described by Gearing et al. (1988) and protects RNA fragments of 644 and 621 nucleotides (Rathjen et al. 1990). A shorter antisense probe, obtained by transcription of pDR2 (Rathien et al. 1990), which contains sequences upstream of the unique Smal restriction site, was used in some cases as it was found to give greater sensitivity and resolution. This probe protects specific RNA fragments of 368 and 345 nucleotides. In each case, the larger protected fragment corresponds to the DIA/LIF-D transcript and the shorter fragment corresponds to the DIA/LIF-M transcript. Antisense human DIA/LIF RNA probes were produced by transcription of HindIII-linearized HpGEMl with T7 polymerase. HpGEMl was constructed by insertion of a human DIA/LIF cDNA fragment from $\mathrm{pCl0}$-6R (Moreau et al. 1988) into the SmaI restriction site of pGEM $3 Z$ (Promega).

The levels of steady-state GAP mRNA were used as a loading control in Northern blot analyses and in protection assays of both mouse and human RNAs. For use in Northern blots, the mGAP cDNA was radiolabeled using the Boehringer Random Primed DNA Labeling Kit. An error was made in the previous description of the GAP control used for ribonuclease protections (Nomura et al. 1989) in that antisense RNA is generated by $\mathrm{Sp} 6$ transcription of BamHI-linearized plasmid. The three bands protected in murine RNAs therefore reflect heterogeneity at the 5 ' rather than the 3 ' end of the mouse GAP mRNA. 
To reduce overexposure of the GAP signal relative to the DIA/ LIF signal, the GAP riboprobe was synthesized in a $15-\mu 1$ reaction volume containing $0.25 \mu \mathrm{l}\left[\alpha^{-32} \mathrm{P}\right] \mathrm{UTP}(800 \mathrm{Ci} / \mathrm{mmole}$, Amersham) and $6 \mu \mathrm{l}$ of $1 \mathrm{mM}$ UTP. This yields probes of 500fold lower specific activity than the DIA/LIF probes. The GAP signal consists of a triplet of protected bands at $\sim 250 \mathrm{bp}$ in murine RNA samples, whereas cross-hybridization yields a protected doublet at $\sim 130$ bp in human RNA samples. We have noticed that the GAP signal can vary with growth rate in cultured cells. In particular, GAP transcription has been found to be an unreliable standard in cells treated with mitomycin $C$ or for protracted periods with inhibitors of protein synthesis.

\section{Fractionation of ES cell-conditioned medium by heparin-} Sepharose affinity chromatography

Serum-free ES cell-conditioned medium was prepared by incubation of CP1 ES cells for $24 \mathrm{hr}$ in defined medium (see above) supplemented with $10 \mathrm{ng} / \mathrm{ml}$ murine DIA/LIF. Under these conditions ES cells continue to proliferate and do not differentiate (A.G. Smith, unpubl.). Conditioned medium $(30 \mathrm{ml})$ was passed through a $0.4-\mu \mathrm{m}$ filter and mixed with $1 \mathrm{ml}$ heparinSepharose CL-6B that had been pre-equilibrated with PBS. After incubation with gentle agitation for $1 \mathrm{hr}$ at $4^{\circ} \mathrm{C}$, the unbound material was decanted and the resin was packed into a $2-\mathrm{ml}$ Econo-column (Bio-Rad). The column was eluted stepwise with increasing concentrations of $\mathrm{NaCl}$ in $50 \mathrm{~mm}$ sodium phosphate (pH 6.8$)$ containing $0.02 \%$ Tween-20. Fractions $(2 \mathrm{ml})$ were concentrated using Centricon-10 microconcentrators (Amicon) before assaying for biological activity.

\section{Acknowledgments}

Research in our laboratory is supported by the Cancer Research Campaign. S.T. was the recipient of a Royal Society Exchange Fellowship. We thank Professor Nicholas Kurti for support, Louis Mahadevan for detailed comments on the manuscript, Alan Wills for RNAs, Ken Johnson and Frank Johnston for photography, and Liz Hirst for excellent technical assistance.

The publication costs of this article were defrayed in part by payment of page charges. This article must therefore be hereby marked "advertisement" in accordance with 18 USC section 1734 solely to indicate this fact.

\section{References}

Abe, E., H. Tanaka, Y. Ishimi, C. Miyaura, T. Hayashi, H. Nagasawa, M. Tomida, Y. Yamaguchi, M. Hozumi, and T. Suda. 1986. Differentiation-inducing factor purified from conditioned medium of mitogen-treated spleen cell cultures stimulates bone resorption. Proc. Natl. Acad. Sci. 83: 59585962.

Almendral, J.M., D. Sommer, H. Macdonald-Bravo, J. Burckhardt, J. Perera, and R. Bravo. 1988. Complexity of the early genetic response to growth factors in mouse fibroblasts. Mol. Cell. Biol. 8: 2140-2148.

Auffray, C. and F. Rougenon. 1980. Purification of mouse immunoglobulin heavy-chain messenger RNAs from total myeloma tumor RNA. Eur. I. Biochem. 107: 303-324.

Baumann, H. and G.G. Wong. 1989. Hepatocyte-stimulating factor-III shares structural and functional identity with leukaemia-inhibitory factor. I. Immunol. 143: 1163-1167.

Conquet, F. and P. Brulet. 1990. Developmental expression of myeloid leukaemia inhibitory factor gene in preimplanta- tion blastocysts and in extraembryonic tissues of mouse embryos. Mol. Cell. Biol. 10: 3801-3805.

Evans, M.J. and M. Kaufman. 1981. Establishment in culture of pluripotential cells from mouse embryos. Nature 292: 154156.

1983. Pluripotential cells grown directly from mouse embryos. Cancer Surv. 2: 185-208.

Gardner, R.L. 1985. Regeneration of endoderm from primitive ectoderm in the mouse embryo: Fact or artifact? I. Embryol. Exp. Morph. 80: 303-326.

Gearing, D.P., N.M. Gough, J.A. King, D.J. Hilton, N.A. Nicola, R.J. Simpson, E.C. Nice, A. Kelso, and D. Metcalf. 1987. Molecular cloning and expression of cDNA encoding a murine myeloid leukaemia inhibitory factor (LIF). EMBO $I$. 6: 3995-4002.

Gearing, D.P., J.A. King, and N.M. Gough. 1988. Complete sequence of murine myeloid leukaemia inhibitory factor (LIF). Nucleic Acids Res. 16: 9857.

Gospodarowicz, D. 1974. Localisation of a fibroblast growth factor and its effect alone and with hydrocortisone on 3T3 cell growth. Nature 249: 123-129.

Green, J.B.A., G. Howes, K. Symes, J. Cooke, and I.C. Smith. 1990. The biological effects of XTC-MIF: Quantitative comparison with Xenopus bFGF. Development 108: 173-183.

Greenberg, M.E., A.L. Hermanowski, and E.B. Ziff. 1986. Effect of protein synthesis inhibitors on growth factor activation of c-fos, c-myc and actin gene transcription. Mol. Cell. Biol. 6: $1050-1057$.

Heath, J.K. 1987. Experimental analysis of teratocarcinoma cell multiplication and purification of embryonal carcinoma-derived growth factor. In Teratocarcinomas and embryonic stem cells: A practical approach (ed. E.J. Robertson), pp. 183-206. IRL Press, Oxford.

Heath, J.K. and A.G. Smith. 1988. Regulatory factors of embryonic stem cells. I. Cell. Sci. (suppl.) 10: 257-266.

-1989. Growth factors in embryogenesis. Br. Med. Bull. 45: 319-336.

Hilton, D.J., N.A. Nicola, N.M. Gough, and D. Metcalf. 1988. Resolution and purification of three distinct factors produced by Krebs ascites cells which have differentiation-inducing activity on murine myeloid leukaemic cell lines. $/$. Biol. Chem. 263: 9238-9243.

Hogan, B.L.M. and R. Tilly. 1977. In vitro culture and differentiation of normal mouse blastocysts. Nature 265: 626-629.

Hooper, M.L. and C. Slack. 1977. Metabolic cooperation in HGPRT $^{+}$and HGPRT ${ }^{-}$embryonal carcinoma cells. Dev. Biol. 55: 271-284.

Ignotz, R.A. and J. Massagué. 1985. Type $\alpha$ transforming growth factor controls the adipogenic differentiation of 3T3 fibroblasts. Proc. Natl. Acad. Sci. 82: 8530-8534.

Jetten, A.M., M.E.R. Jetten, and M.I. Sherman. 1979. Stimulation of differentiation of several murine embryonal carcinoma cell lines by retinoic acid. Exp. Cell Res. 124: 381391.

Joyce, M.E., A.B. Roberts, M.B. Sporn, and M.E. Bolander. 1990. Transforming growth factor- $\beta$ and the initiation of chondrogenesis and osteogenesis in the rat femur. \%. Cell Biol. 110: 2195-2207

Kola, I., A. Davey, and N.M. Gough. 1990. Localization of the murine leukaemia inhibitory factor gene near the centromere on chromosome 11. Growth Factors 2: 235-240.

Leary, A.G., G.G. Wong, S.C. Clark, A.G. Smith, and M. Ogawa. 1990. Leukemia inhibitory factor/differentiation-inhibiting activity/human interleukin for DA cells augments proliferation of human hemopoietic stem cells. Blood 75: 1960-1964. 
Lehnert, S.A. and R.J. Akhurst. 1988. Embryonic expression of TGF beta type-1 RNA suggests both paracrine and autocrine mechanisms of action. Development 104: 263-273.

Lovell-Badge, R.H. and M.J. Evans. 1980. Changes in protein synthesis during differentiation of embryonal carcinoma cells, and a comparison with embryo cells. J. Embryol. Exp. Morphol. 59: 187-206.

Mahadevan, L.C., A.J. Wills, E.A. Hirst, P.D. Rathjen, and J.K. Heath. 1990. 2-Aminopurine abolishes EGF- and TPA-stimulated pp33 phosphorylation and c-fos induction without affecting the activation of protein kinase C. Oncogene 5: 327-355.

Martin, G.R. 1981. Isolation of a pluripotent cell line from early mouse embryos cultured in medium conditioned by teratocarcinoma stem cells. Proc. Natl. Acad. Sci. 78: 7634-7638.

Massagué, J., S. Cheifetz, T. Endo, and B. Nadal-Ginard. 1986. Type $\beta$ transforming growth factor is an inhibitor of myogenic differentiation. Proc. Natl. Acad. Sci. 83: 8206-8210.

McBurney, M.W. and B.J. Rogers. 1982. Isolation of male embryonal carcinoma cells and their chromosomal replication patterns. Dev. Biol. 89: 503-508.

Metcalf, D and D.P. Gearing. 1989. Fatal syndrome in mice engrafted with cells producing high levels of the leukaemia inhibitory factor. Proc. Natl. Acad. Sci. 86: 5948-5952.

Moreau, J-F., D.D. Donaldson, F. Bennett, J. Witek-Gianotti, S.C. Clark, and G.G. Wong. 1988. Leukaemia inhibitory factor is identical to the myeloid growth factor human in terleukin for DA cells. Nature 336: 690-692.

Mori, M., K. Yamaguchi, and K. Abe. 1989. Purification of a lipoprotein lipase-inhibiting protein produced by a melanoma cell line associated with cancer cachexia. Biochem. Biophys. Res. Comm. 160: 1085-1092.

Nichols, J., E.P. Evans, and A.G. Smith. 1990. Establishment of germ-line competent embryonic stem (ES) cells using differentiation inhibiting activity. Development 10 (in press).

Nomura, S., B.L. Hogan, A.J. Wills, J.K. Heath, and D.R. Edwards. 1989. Developmental expression of tissue inhibitor of metalloproteinase (TIMP) RNA. Development 105: 575583.

Rathjen, P.D., S. Toth, A. Willis, J.K. Heath, and A.G. Smith. 1990. Differentiation inhibiting activity is produced in matrix-associated and diffusible forms that are generated by alternate promoter usage. Cell 62: 1105-1114.

Roberts, A.B., M.B. Sporn, R.K. Assoian, J.M. Smith, N.S Roche, L.M. Wakefield, U.I. Heine, L.A. Liotta, V. Falanga, J.H. Rehrl, and A.S. Fanci. 1986. Transforming growth factor type $\beta$ : Rapid induction of fibrosis and angiogenesis in vivo and stimulation of collagen formation in vitro. Proc Natl. Acad. Sci. 83: 4167-4171.

Robertson, E.J. 1986. Pluripotential stem cell lines as a route into the mouse germ line. Trends. Genet. 2: 9-13.

Rossant, J. and L. Ofer. 1977. Properties of embryonic ectoderm isolated from postimplantation mouse embryos. I. Embryol. Exp. Morphol. 39: 183-194.

Rubin, C.S., A. Hirsch, C. Fung, and O.M. Rosen. 1978. Development of hormone receptors and hormonal responsiveness in vitro. J. Biol. Chem. 253: 7570-7578.

Rudnicki, M.A. and M.W. McBurney. 1987. Cell culture methods and induction of differentiation of embryonal carcinoma cell lines. In Teratocarcinomas and embryonic stem cells: A practical approach (ed. E.J. Robertson), pp. 19-49. IRL Press, Oxford.

Schofield, R. 1978. The relationship between the spleen colony-forming cell and the haemopoietic stem cell. A hypothesis. Blood Cells 4: 4-7.

Shipley, G.D., M.R. Pittelkow, J.J. Wille, Jr., R.E. Scott, and H.L.
Moses. 1986. Reversible inhibition of normal human prokeratinocyte proliferation by type beta transforming growth factor-growth inhibitor in serum-free medium. Cancer Res. 46: $2068-2071$.

Slack, J.M.W., B.G. Darlington, J.K. Heath, and S.F. Godsave. 1987. Mesoderm induction in early Xenopus embryos by heparin-binding growth factors. Nature 326: 197-200.

Smith, A.G. 1990. Culture and differentiation of embryonic stem cells. I. Tissue Culture Methods (in press).

Smith, A.G. and M.L. Hooper. 1987. Buffalo rat liver cells produce a diffusible activity which inhibits the differentiation of murine embryonal carcinoma and embryonic stem cells. Dev. Biol. 121: 1-9.

Smith, A.G., J.K. Heath, D.D. Donaldson, G.G. Wong, J. Moreau, M. Stahl, and D. Rogers. 1988. Inhibition of pluripotential embryonic stem cell differentiation by purified polypeptides. Nature 336: 688-690.

Smith, J.C., B.M.J. Price, K. van Nimmen, and D. Huylebroeck. 1990. Identification of a potent Xenopus mesoderm-inducing factor as a homologue of activin A. Nature 345: 729-731.

Sporn, M.B. and A.B. Roberts. 1988. Peptide growth factors are multifunctional. Nature 332: 217-219.

Strickland, S. and V. Mahdavi. 1978. The induction of differentiation in teratocarcinoma cells by retinoic acid. Cell 15: $393-403$.

Williams, R.L., D.J. Hilton, S. Pease, T.A. Willson, C.L. Stewart, D.P. Gearing, E.F. Wagner, D. Metcalf, N.A. Nicola, and N.M. Gough. 1988. Myeloid leukaemia inhibitory factor maintains the developmental potential of embryonic stem cells. Nature 336: 684-687.

Yamamori, T., K. Fukada, R. Aebersold, S. Korsching, M-J. Fann, and P.H. Patterson. 1989. The cholinergic neuronal differentiation factor from heart cells is identical to leukaemia inhibitory factor. Science 246: 1412-1416. 


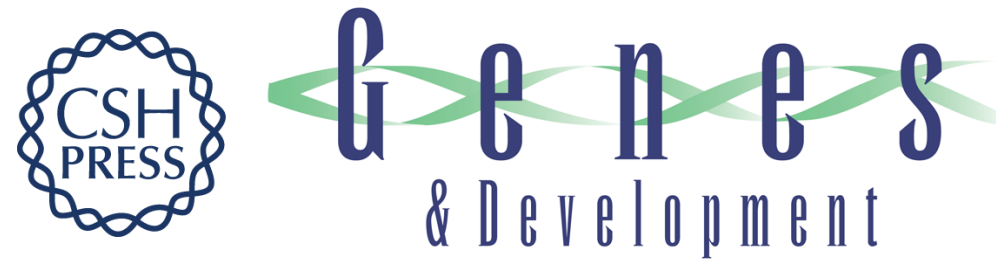

\section{Developmentally programmed induction of differentiation inhibiting activity and the control of stem cell populations.}

P D Rathjen, J Nichols, S Toth, et al.

Genes Dev. 1990, 4:

Access the most recent version at doi:10.1101/gad.4.12b.2308

References This article cites 48 articles, 19 of which can be accessed free at:

http://genesdev.cshlp.org/content/4/12b/2308.full.html\#ref-list-1

License

Email Alerting

Service

Receive free email alerts when new articles cite this article - sign up in the box at the top right corner of the article or click here.

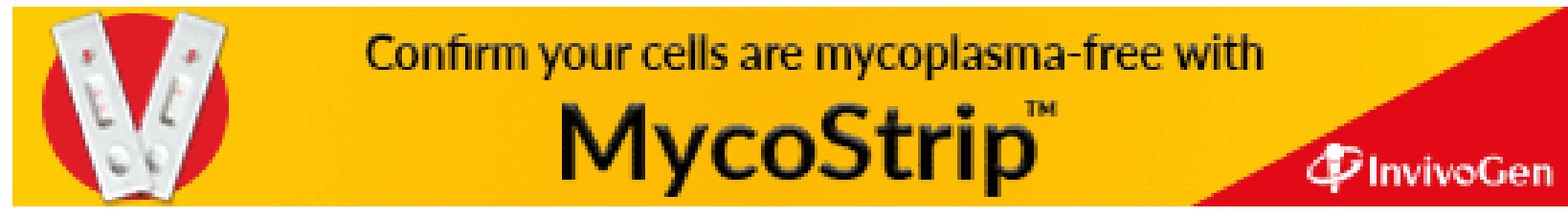

